\title{
O PROCESSO DE INCORPORAÇÃO DE ESTRATÉGIAS EMERGENTES POR SISTEMAS DE CONTROLE DE GESTÃO: EVIDÊNCIAS A PARTIR DE UM ESTUDO DE CASO COM BSC
}

\author{
iD Luiz Gustavo Vaz de Melo ${ }^{1}$ (i) Maria Elisa Brandão Bernardes ${ }^{2}$ \\ ${ }^{1}$ Fundação Dom Cabral-FDC. Nova Lima, Minas Gerais - Brasil.luizgustavovazdemelo@gmail.com \\ ${ }^{2}$ Fundação Dom Cabral-FDC. Nova Lima, Minas Gerais - Brasil.mariaelisa@fdc.org.br
}

Resumo

Objetivo do estudo: O estudo teve como objetivo descrever um processo de incorporação de estratégias emergentes por uma organização que utiliza um Sistema de Controle de Gestão (SCG), baseado no Balanced Scorecard (BSC).

Metodologia/abordagem: Abordagem processual, por meio da qual o fenômeno foi examinado como uma sequência de eventos ao longo do tempo, nos quais a participação de indivíduos de diferentes níveis e posições foi considerada. O método empregado foi o estudo de caso, que privilegia levantamentos qualitativos, tais como a interação entre o SCG e as estratégias deliberadas ou emergentes.

Originalidade/relevância: Ampliou o conhecimento do processo de implementação através do uso de SCG, baseado no BSC, por meio do qual, apesar do rígido controle, uma nova estratégia emergiu e foi incorporada à estratégia deliberada. Raros são os estudos que, abordando as duas frentes teóricas (estratégia emergente e controle de gestão), oferecem uma descrição detalhada do processo que as integra.

Principais resultados: Os resultados evidenciaram que o uso do BSC, como SCG, viabiliza a comunicação e o desdobramento de objetivos estratégicos alinhados e priorizados, o monitoramento da implementação através de revisões e é compatível com o desenvolvimento de uma estratégia emergente. Também explicaram que a emergência ocorreu de maneira lenta e incremental. Além disso, sua integração só foi possível graças aos movimentos contínuos e progressivos de constrições internas, oriundas da base da organização, e externas, advindas de diversos atores do mercado. Contribuições teóricas/metodológicas: Contribuiu para elucidar o processo de implementação de estratégias através do uso de um SCG baseado no BSC, com suas limitações, e também a dinâmica da evolução de uma estratégia emergente, desde o seu surgimento até a sua incorporação no plano, relevando a participação de diferentes stakeholders no processo.

Palavras-chave: Balanced Scorecard. Estratégia emergente Implementação. Processo.

\section{THE INCORPORATION PROCESS OF EMERGENT STRATEGIES BY MANAGEMENT CONTROL SYSTEMS:} EVIDENCES FROM A CASE STUDY WITH BSC

\section{Abstract}

Objective: The purpose of the study was to describe an incorporation process of emergent strategies by an organization that uses a Management Control System (MCS) based on the Balanced Scorecard (BSC).

Methodology/approach: The process approach, by which the phenomenon was examined as a sequence of events over time, where the participation of individuals of different levels and positions was considered. The method used was the case study, which privileges qualitative surveys, such as the interaction between the MCS and the deliberate or emergent strategies.

Originality/relevance: It expanded the knowledge of the implementation process through the use of MCS, based on the BSC, by which, despite strict control, a new strategy emerged and was incorporated into the deliberate strategy. Studies that approach the two theoretical fronts (emergent strategy and management control) are rare. Here we offer a detailed description of the process that integrates them.

Main results: The results evidenced that the use of a MCS, such as the BSC, makes the communication and the development of aligned and prioritized strategic goals feasible, as well as the monitoring of implementation through reviews, and it is compatible with the development of an emergent strategy. It also explained that it occurred in a slow and incremental way. Furthermore, its integration was only possible thanks to the continuous and progressive movements of internal constraints, arising from the base of the organization, and external, from different market players.

Theoretical/methodological contributions: The study contributed to clarify the strategy implementation process, through the use of a MCS, such as the BSC, with its limitations, and also on the dynamics of the evolution of an emergent strategy, from its manifestation to its incorporation into the plan, highlighting the participation of different stakeholders in the process.

Keywords: Balanced Scorecard. Emergent strategy. Implementation. Process.

\section{EL PROCESO DE INCORPORACIÓN DE ESTRATEGIAS EMERGENTES POR SISTEMAS DE CONTROL DE GESTIÓN: EVIDENCIAS A PARTIR DE UN ESTUDIO DE CASO CON BSC}

\begin{abstract}
Resumen
Objetivo del estudio: El estudio tuvo como objetivo describir un proceso de incorporación de estrategias emergentes por una organización que hace uso de un Sistema de Control de Gestión (SCG), basado en el Balanced Scorecard (BSC)

Metodología / enfoque: Enfoque procesual, a través de la cual el fenómeno fue examinado como una secuencia de eventos a lo largo del tiempo, en los cuales la participación de individuos de diferentes niveles y posiciones fue considerada. El método empleado fue el estudio de caso, que privilegia levantamientos cualitativos, tales como la interacción entre SCG y las estrategias deliberadas o emergentes.

Originalidad / relevancia: Amplió el conocimiento del proceso de implementación a través del uso de SCG, por medio de lo cual, a pesar del rígido control, una nueva estrategia emergió y fue incorporada a la estrategia deliberada. Raros son los estudios que, abordando las dos frentes teóricas (estrategia emergente y control de la gestión), ofrecen una descripción detallada del proceso que las integra.

Resultados principales: Los resultados evidenciaron que el uso del BSC, como SCG, permite la comunicación y el despliegue de objetivos estratégicos alineados y priorizados, el monitoreo de la implementación a través de revisiones y es compatible con el desarrollo de una estrategia emergente. También se explicó que la emergencia ocurrió de manera lenta e incremental. Además, su integración fue posible solo gracias a los movimientos continuados y progresivos de construcciones internas, oriundas de la base de la organización, y externas, provenientes de diversos actores del mercado. Contribuciones teóricas / metodológicas: Contribuyó para elucidar el proceso de implementación de estrategias a través del uso de un SCG, basado en el BSC, con sus limitaciones, y también la dinámica de la evolución de una estrategia emergente, desde su surgimiento hasta su incorporación en el plan, relevando la participación de diferentes stakeholders en el proceso.
\end{abstract}

Palabras clave: Balanced Scorecard. Estrategia emergente. Implementación. Proceso.

Cite as / Como citar

American Psychological Association (APA)

Melo, L. G. V., \&, Bernardes, M. E. B. (2020, July/Sept.). O processo de incorporação de estratégias emergentes por sistemas de controle de gestão: evidências a partir de um estudo de caso com BSC. Iberoamerican Journal of Strategic Management (IJSM), 19(3), 90-115. https://doi.org/10.5585/riae.v19i3.17290. 


\section{Introdução}

Percebe-se, hoje em dia, uma busca constante das empresas pelo desenvolvimento de um planejamento estratégico estruturado que defina objetivos e metas para orientar investimentos. Além da definição da melhor estratégia, as organizações também se preocupam em implementá-la de forma eficiente e, para tal fim, elas têm empregado Sistemas de Controle de Gestão (SCG). Com efeito, pesquisas realizadas por Neely (2008) sugeriram que $85 \%$ das principais organizações nos Estados Unidos e na Europa apresentaram iniciativas de implementação usando SCG para o monitoramento e gestão do desempenho da estratégia. A pesquisa também concluiu que o Balanced Scorecard (BSC) é o sistema usado em, pelo menos, $60 \%$ dessas organizações.

No entanto, pode-se considerar que muitas vezes uma implementação da estratégia pode falhar por questões que estão fora do controle da empresa, por exemplo, quando um concorrente ganha uma vantagem estratégica de mercado primeiro ou quando há mudanças de comportamento do público consumidor. Nessas circunstâncias, os processos internos e as ações gerenciais precisam ser repensados ou recriados. Uma maneira de realizar adequações de maneira eficaz é estar atento às estratégias emergentes, conceito originalmente introduzido por Mintzberg (1978), que trata das estratégias que emergem hierarquicamente de baixo para cima na organização, através da sucessão de padrões de ações à despeito de um plano existente. Mas a questão surge porque, considerando a rigidez dos sistemas de controle (que são majoritariamente hierárquicos) e a fluidez das estratégias emergentes, esse não é um processo trivial. Assim, o benefício do uso de um SCG, como o BSC, residiria não apenas na sua capacidade de monitorar o processo de implementação de uma estratégia deliberada, mas também em uma desejável flexibilidade para incorporar eventuais mudanças oriundas de uma estratégia emergente.

Kaplan e Norton (1996, pp. 251-252), idealizadores do Balanced Scorecard, reconhecem que estratégias emergentes podem surgir em níveis hierarquicamente inferiores da organização e reconhecem também que a estratégia planejada, com base nas melhores intenções e informações disponíveis, podem não ser apropriadas ou perenemente válidas em ambientes de alta competitividade e em constante mudança. Os autores recomendam que as organizações precisam aprender a rever suas estratégias, quando o cenário mudar. No entanto, isso não parece ser claramente compatível com o tipo de controle proposto pelo BSC, descrito como um método altamente mecânico e hierarquicamente top down, conforme lembra Norreklit (2000). Na verdade, pouco se sabe sobre como a incorporação de estratégias emergentes tem acontecido nas organizações bem-sucedidas. Ainda permanecem lacunas no entendimento do processo de implementação nos casos nos quais, apesar do rígido monitoramento através de um SCG, com base no BSC, estratégias novas, diferentes do que fora planejado, emergem (Americano \& Fleck, 2015). Sendo assim, a pesquisa aqui relatada se interessou justamente em entender como ocorre o processo de incorporação de estratégias emergentes por uma organização que utiliza um sistema de controle de gerenciamento com base no Balanced Scorecard. 
A pesquisa adotou a abordagem processual (Pettigrew, 1992; Whittington, 2007; Langley, 2007), que examina a estratégia como uma sequência de eventos ao longo do tempo e nos quais é considerada a participação de indivíduos de diferentes níveis e diferentes posições na organização. $\mathrm{O}$ método empregado foi o estudo do caso do Centro Educacional Leonardo Da Vinci (CEDLV), que possuía um SCG baseado no BSC e que reconheceu e anexou uma estratégia emergente ao seu plano deliberado. Através da análise foi possível se identificar que, se por um lado o uso do BSC evidenciou a primazia do controle formal com limitada abertura para contribuição de líderes operacionais (Antonsen, 2014; Norreklit, 2000); por outro lado, o reconhecimento de uma estratégia emergente de fato aconteceu, e foi graças à uma combinação de movimentos de stakeholders internos, oriundos da base da organização e de stakeholders externos, advindos do mercado e da comunidade envolvida. Foi identificado que a incorporação ocorreu de maneira evolutiva, descrita em cinco fases: desde a percepção da necessidade advinda do contexto, seguida do enfrentamento de resistências internas, a terceira fase da avaliação das possibilidades e as fases finais de inclusão no plano e aprimoramento da nova estratégia. As fases se amalgamaram com a dupla constrição. Sendo assim, o processo foi descortinado e uma explicação conceitual foi desenvolvida, com contribuições teóricas e para a prática organizacional.

Este artigo se inicia com uma breve revisão das literaturas, tanto sobre o uso dos Sistemas de Controle e seu expoente, o BSC, como sobre estratégias emergentes. Na sequência, é apresentada a metodologia da pesquisa, que investigou o caso CEDLV. O processo é descrito desde o surgimento dos primeiros movimentos até a total incorporação da estratégia e as respectivas medidas de aprimoramento. Em seguida, a análise organiza os acontecimentos nas mencionadas cinco fases, e um ciclo de evolução, com identificação das intercaladas constrições internas e externas, é apresentado. O artigo é concluído apresentando pistas para novas pesquisas.

Sistema de controle de gestão e o BSC

Kaplan e Norton (2006 p.103) definem um SCG como um conjunto de processos e práticas utilizados para alinhar e controlar uma organização. Questões que envolvem a dinâmica de se controlar uma empresa, o processo de estruturação das estratégias organizacionais e a avaliação do comportamento e desempenho subsequentes da organização são o cerne do processo de controle de gestão (Kaplan \& Norton, 2006). Os autores afirmam que os SGCs incluem os procedimentos para o planejamento e implementação de estratégias e operações, para a definição de orçamento de capital e operacional, para medir e recompensar o desempenho, e para reportar o progresso e realizar reuniões. Gomes e Salas (1997) certificam que um SGC tem como objetivo promover o sucesso das empresas por meio do amplo engajamento das pessoas no processo de gestão, visando atingir objetivos individuais e de negócios. Assim, o objetivo do uso do SCG pelos gestores seria para que eles pudessem avaliar se suas principais decisões estão sendo incorporadas nas atividades departamentais e determinar se as 
Melo, L. G. V., \&, Bernardes, M. E. B. (2020, July/Sept.). O processo de incorporação de estratégias emergentes por sistemas de controle de gestão: evidências a partir de um estudo de caso com BSC

estratégias deliberadas estão influenciando de fato no desempenho organizacional (Daft \& Macintoch, 1984). Para Simons (1991), um SCG compreenderia sistemas de monitoramento da performance para oferecer aos gestores inclusive a possibilidade de adaptação na medida do avanço da implementação da estratégia.

Outro ponto defendido por Kaplan e Norton (2006) é que um SCG com base no BSC é a melhor maneira de alinhar a estratégia e a organização. Segundo os autores, mapas são capazes de fornecer aos executivos um quadro abrangente que traduz os objetivos estratégicos organizacionais em um conjunto coerente de medidas de desempenho. Eles afirmam que, muito mais do que um exercício de medição, o BSC é um sistema de gerenciamento que pode motivar melhorias significativas em áreas críticas como produto, processo, cliente e desenvolvimento de mercado. Os referidos autores complementam que o BSC apresenta quatro perspectivas: financeira, cliente, processo e aprendizagem, que fornecem equilíbrio entre medidas externas, como receitas operacionais, e medidas internas, como o desenvolvimento de novos produtos. Além disso, eles afirmam que esse conjunto equilibrado revela o balanceamento necessário para se atingir objetivos no futuro. Kaplan e Norton (2008) preconizam o uso de diversas ferramentas de gestão estratégica na formulação, como a análise SWOT, a identificação de forças competitivas e o mapa estratégico (com as quatro perspectivas em cadeias de objetivos relacionados). Eles também recomendam ferramentas para monitoramento e controle da implementação: o balanced scorecard com a tradução dos objetivos em alvos e métricas; os portfólios de iniciativas com a devida alocação de recursos para os diferentes projetos e/ou programas; e uma planilha temporal com as atividades a serem empreendidas (Kaplan e Norton, 2008). Segundo os mesmos, todas as etapas devem ser orquestradas em diferentes tipos de reuniões de acompanhamento.

Kaplan e Norton (2001) sustentam que o BSC visa ajudar as empresas a estabelecerem ações para criar valor para o acionista, satisfazer as expectativas dos demais interessados, implementar estratégias definidas e melhorar os serviços de gestão, os processos internos, a aprendizagem e a inovação. Como há uma perspectiva voltada para o feedback e a aprendizagem, Kaplan e Norton (1996) ainda argumentam que as empresas podem adquirir a capacidade para a aprendizagem estratégica através dos feedbacks constantes e revisão de processos existentes para direcionar a empresa.

Os SCGs atuais procuram adicionar novos índices aos indicadores econômicos, financeiros, de qualidade e de produtividade (Jordão \& Casas Novas, 2013), acrescentando outros relacionados ao clima organizacional, à cultura, aos fatores ambientais, à posição competitiva, aos interesses das partes interessadas (Gomes \& Salas, 1997) e, em particular, à satisfação do cliente com produtos, serviços e processos. Nesse sentido, Jordão e Casas Novas (2013) salientam que a implementação bem-sucedida do modelo depende do envolvimento de todas as partes interessadas (de gerentes a pessoas em níveis operacionais) de acordo com os objetivos e prioridades estabelecidos no planejamento estratégico.

No entanto, conforme salienta Simons (1995), algumas questões limitam a utilização do SCG para a implementação da estratégia de maneira flexível. O autor lembra que o SCG não pressupõe qualquer observação contínua das ações e resultados dos concorrentes ou o monitoramento de 
desenvolvimentos tecnológicos, o que pode significar que o foco do modelo seja mais estático do que dinâmico. O uso do modelo pode não levar em consideração incertezas estratégicas em termos de risco envolvido em eventos que possam ameaçar ou invalidar a estratégia atual e não questiona quais as premissas e questões externas que podem impedir a realização da estratégia deliberada pela empresa.

Daft e Macintosh (1984) alertam que os SCGs podem ser considerados como um componente da estrutura burocrática da organização e, nessa qualidade, representam um mecanismo impessoal, limitando a possibilidade de identificação de estratégias emergentes. De fato, Antonsen (2014), ao pesquisar um grande banco norueguês, concluiu que o uso do BSC ampliou o controle formal e reduziu o escopo dos funcionários para contribuir com novas ideias. Segundo sua pesquisa, o controle formal fortaleceu o aprendizado adaptativo sob a forma de fluxo de informações da alta gerência para a média gerência e reduziu o foco da média gerência no comportamento de trabalho criticamente reflexivo, inibindo a comunicação de novas ideias para a alta administração. $\mathrm{O}$ autor confirmou as visões de Norreklit (2000) e de Voelpel, Leibold e Eckhoff (2006) de que o BSC influencia o desenvolvimento organizacional como um processo interno controlado pela alta gerência.

Para Simons (1994), idealmente, um SCG deve acomodar estratégias deliberadamente planejadas, mas também estratégias incrementais que podem surgir ao longo do tempo. Jaworski e Macinnis (1989) mostraram em seus estudos uma forte relação entre o tipo de SCG em uso e o desempenho da empresa. Eles apresentaram que a concepção e a estruturação de um sistema de controle em um esforço de implementação são uma decisão crítica, visto que estes precisam ser flexíveis para evoluir à medida que um esforço de implementação avança. Além disso, Jazayeri e Scapens (2008) argumentam que o SCG deve ser estruturado para permitir que as estratégias surjam dentro da organização também hierarquicamente, de baixo para cima.

No entanto, ainda é necessário se buscar entender, como o uso de sistemas de controle (como o BSC) pode oferecer espaço, na prática, para que estratégias emergentes se desenvolvam na organização que possui esse controle tão apurado.

\section{Estratégias emergentes}

O termo estratégia emergente foi introduzido por Mintzberg (1978, p. 80), referindo-se, essencialmente, a um padrão de decisões coerentes, não necessariamente planejadas, à despeito da existência do plano ou de uma estratégia deliberada, que a organização adota ao longo do tempo. Para o autor, todo processo estratégico possui dois aspectos: um deliberado e outro emergente, pois, da mesma forma que a formulação puramente deliberada impede a aprendizagem, uma formulação puramente emergente impede o controle (Mintzberg, 1987, p. 425). Para tanto, é necessária uma atitude atenta da organização para traduzir e incorporar as mudanças do contexto em respostas estratégicas.

Balogun e Johnson (2005) argumentam que a estratégia que emerge ao longo do tempo tem a intenção de ir ao encontro e acomodar uma nova realidade em mudança. Eles definem a estratégia 
emergente como um conjunto de ações ou comportamento consistentes com "intervenções e planos de mudança que são traduzidos em ação por meio desses processos, transformando a mudança de cima para baixo em um processo emergente e imprevisível " (Balogun \& Johnson, 2005, p. 1575). Assim, os autores complementam que a estratégia emergente representa o que uma organização está aprendendo que funciona na prática. Hamel (2009, pp. 91-94), inclusive, recomenda que as empresas "reinventem a estratégia como processo emergente" a fim de "reinventar a gestão e torná-la mais relevante para um mundo volátil".

A estratégia emergente pode ter a sua origem em diversas fontes. Bower (1970) já descreveu que as estratégias podem surgir como resultado de iniciativas vindas de níveis mais baixos da hierarquia e induzidas pela alta direção com certos mecanismos administrativos, como a organização formal e o sistema de recompensas utilizado pelos gestores. O autor propôs o modelo de duplo fluxo de influências: de cima para baixo, a alta direção influencia o comportamento de gerentes de nível inferior por meio do estabelecimento de objetivos estratégicos e de mecanismos de controle; de baixo para cima, os gerentes operacionais pleiteiam novos projetos de investimento que os gerentes intermediários levam à alta direção para aprovação. Nesse caso, uma nova estratégia corporativa pode emergir do processo.

Burgelman (1983) ressaltou o papel fundamental da média gerência para esse fim. Segundo o autor, mesmo quando a estratégia corporativa já está estabelecida e sendo executada, a média gerência pode tomar iniciativas importantes que estejam fora da estratégia em curso, porque resultam de suas percepções sobre as mudanças no contexto. Mirabeau e Maguire (2014) identificaram que a estratégia emergente se origina como um comportamento estratégico autônomo: projetos que, apesar da dissonância com o conceito predominante da estratégia deliberada, são lançados como resultado da solução local de problemas. Estes projetos autônomos tornam-se padrões de ação duradouros através da mobilização de um suporte mais amplo para impulsioná-los, manipulando o contexto estratégico para legitimá-los, construindo-os como consoantes com o conceito predominante e alterando os planos para incorporar os projetos dentro das unidades organizacionais, das rotinas e dos objetivos. Mirabeau e Maguire (2014) veem a estratégia como um processo iterativo de alocação de recursos e argumentam que uma estratégia emergente deve ser percebida como consequência da mobilização de um apoio organizacional mais amplo. Os seus estudos apontam a importância do papel das "práticas de articulação de estratégias" na formação de estratégias emergentes e explicam por que alguns comportamentos estratégicos autônomos se tornam "efêmeros" e desaparecem ao invés de durarem para se tornarem estratégias emergentes (Mirabeau e Maguire, 2014, p.1211). De fato, Lowe \& Jones (2004) já haviam identificado que, mesmo quando há uso de SCG, as estratégias emergentes se desenvolvem em meio a intensas discussões entre os diferentes atores organizacionais em suas interações sociais. Nesses casos, conforme lembra Mariotto (2003), o papel da direção é o de incentivar seletivamente o crescimento das estratégias emergentes, em alguns casos eliminando-as e em outros até permitindo que elas tomem o lugar de estratégias pretendidas. 
Em suma, a literatura é inequívoca em sua evidência da importância do reconhecimento das estratégias emergentes, mas os estudos que explicam a sua formação ainda não estão concluídos. Além disso, enquanto os gerentes operacionais e intermediários figuram proeminente na literatura sobre a estratégia emergente, as atividades que realizam para que isto aconteça ainda estão sendo desvendadas. Sobretudo em um processo estratégico que conta com o acompanhamento de um SCG com base no BSC, onde a margem de manobra para participação das lideranças operacionais é questionada, o processo de emergência de uma estratégia e sua incorporação pelo sistema é obscuro. A pesquisa que será apresentada a seguir contribui para suprir esta lacuna.

\section{Metodologia de pesquisa}

Esse estudo adotou a abordagem processual (Pettigrew, 1992; Whittington, 2007; Langley, 2007), cuja estratégia é examinada como uma sequência de eventos ao longo do tempo e nos quais a participação de indivíduos de diferentes níveis (alta gestão, intermediário e operacional) e diferentes posições (interna e externa à organização) é considerada.

O método empregado foi o estudo de caso, que demonstra ser o mais adequado para a investigação processual, em que levantamentos qualitativos, como a interação entre SCG e estratégias deliberadas ou emergentes, são necessários e não se encaixam facilmente em medidas quantitativas (Yin, 1994). Além disso, a proposta investigativa implica em entrar na organização para recuperar a dinâmica da relação entre controle e emergência da estratégia. Por fim, o uso do caso permite que ideias e propostas sejam desenvolvidas para um estudo mais aprofundado (Eisenhardt, 1989; Noda \& Bower, 1996), além de possibilitarem verificar a prática de novas abordagens teóricas em gestão (Mariotto, Zanni e De Moraes, 2014), ainda que limitem as generalizações.

A pesquisa foi realizada numa empresa do setor de educação do ensino básico, fundamental e médio de Brasília (DF), chamada Centro Educacional Leonardo Da Vinci (CEDLV). As principais características para a escolha da empresa foram: ser uma empresa consolidada com quase 50 anos de existência, possuir um sistema de controle do gerenciamento (SCG) com base no BSC e ter reconhecido o surgimento de uma estratégia emergente que foi incorporada ao planejamento estratégico da organização.

Foram coletados dados primários entre abril e junho de 2018 através de 11 entrevistas em profundidade. Primeiramente foi realizada uma entrevista ampla com o diretor responsável, para avaliar a aderência do caso ao tema da pesquisa proposta. Após confirmada a aderência, foram elaboradas e realizadas entrevistas semiestruturadas com outros 10 colaboradores da organização. O roteiro buscou o relato do processo na visão de cada um dos entrevistados: uma descrição geral do processo de implementação de estratégias no CEDLV; um relato mais detalhado do processo específico em investigação, considerando-se atores e cenários internos e externos; e finalmente, sobre a incorporação 
da nova estratégia ao plano. Após realizadas todas as sessões de entrevistas, o material foi consolidado em uma linha do tempo.

A escolha dos entrevistados foi baseada em seus cargos dentro da instituição, respeitando uma amostra mínima de três profissionais de cada nível hierárquico (estratégico, tático e operacional), sendo 3 diretores, 4 gerentes e 4 professores. Esta escolha também levou em consideração os profissionais apontados com maior envolvimento com a emergência da estratégia e com mais de 10 anos de empresa, uma vez que o histórico dos fatos tenha se iniciado em 2009. Todas as entrevistas foram gravadas com o devido consentimento dos entrevistados. Para preservar a identidade dos entrevistados, foram criados códigos: Entrevistado1 (E1), Entrevistado (E2) e assim sucessivamente.

Além das entrevistas, foram coletados dados secundários por meio de documentos disponibilizados pela empresa, como: mapa estratégico e sistema de controle de indicadores, encartes dos programas extracurriculares oferecidos pelo colégio, site institucional, manual do sistema de gestão ambiental e matérias publicadas em Revistas Internas. Nos documentos, buscou-se identificar informações e dados sobre o processo que pudessem complementar as entrevistas.

Foi realizada uma análise de conteúdo das entrevistas e documentos, através da criação de categorias de grade aberta (Vergara, 2005). Assim, os dados foram categorizados de acordo com as respostas recebidas para efeito de confirmação ou contraposição das argumentações dos entrevistados. Superada esta etapa, foram realizadas outras sessões de entrevistas com três dos entrevistados para dirimir dúvidas encontradas. As repostas foram novamente categorizadas de forma a obter um entendimento melhor sobre a percepção dos entrevistados com relação aos temas abordados. A seguir o caso será apresentado, primeiramente de acordo com a sequência de eventos com a participação dos diferentes atores e, em seguida, com uma análise destrinchada.

\section{O caso do centro educacional Leonardo da Vinci}

A escola e o uso do BSC

O CEDLV iniciou suas atividades educacionais em Brasília no ano de 1969 ofertando cursos preparatórios aos exames supletivos e vestibulares. Em 1975, construiu sua sede própria, chamada Unidade Sul, dispondo de instalações amplas, onde passou a oferecer o ensino de $2^{\circ}$ grau regular (atual ensino médio) e a partir de 1991 passou a oferecer também o atual ensino fundamental. Segundo o Correio Brasiliense (2018), o Centro Educacional Leonardo da Vinci está posicionado entre as melhores instituições privadas de educação básica do Distrito Federal, conforme ranking do IDEB - Índice de Desenvolvimento de Educação Básica. Hoje a escola possui em torno de 6000 alunos e conta com um corpo docente superior a 300 professores e 200 funcionários em suas três unidades. Conforme relato dos entrevistados, a escola sempre teve preocupação com a melhoria contínua de seus serviços e de sua gestão. Com esse objetivo, inicialmente recorreu ao apoio do Sistema S (SESI, SENAI, SENAC, SEBRAE) e criou, em 1997, o Programa de Qualidade do Leonardo da Vinci. A prática de planejamento 
Estratégico já existia na organização, mas em fevereiro de 2008 foi implantado SCG, baseado no BSC, com o objetivo declarado de assegurar a plena execução da estratégia conforme o planejado, criando um panorama de supervisão para os representantes da alta gerência. Para a gestão e acompanhamento do BSC, foi constituído um Grupo Estratégico, composto pelos diretores Financeiro, Administrativo, Pedagógico, a Gerente de RH e de Pessoal, a Tesoureira, o Gerente de TI e o Gerente Administrativo e Financeiro, além de seus mantenedores. O principal objetivo do grupo era garantir aderência estratégica às mudanças de realidade empresarial e do mercado, através da plena execução do planejamento estratégico.

No que se refere aos fatores críticos de sucesso para um bom funcionamento de um SCG com a comunicação clara da estratégia, o monitoramento dos resultados das ações implementadas e a utilização de incentivos e sanções, conforme descrito por Bernardes, Dias e Drummond (2008), a escola adota os seguintes procedimentos:

- Comunicação clara da estratégia: são realizadas duas reuniões anuais, no início de cada semestre letivo, na qual é apresentado o mapa estratégico do BSC com os status dos principais indicadores e as principais preocupações e desafios da empresa. Foi relatada a preocupação da alta administração com o envolvimento dos colaboradores da base, principalmente dos professores e coordenadores. No entanto, merece ser notado que, apesar desse cuidado, as pesquisas de clima apontam que o item que precisa de maior atenção é justamente a comunicação interna (ainda que a escola alcance um grau de satisfação acima de $90 \%$ entre professores e funcionários). Foi possível verificar, através das entrevistas, que o controle formal top-down, estabelecido pelo BSC, fortalece a disseminação de diretrizes, direcionamentos estratégicos e o aprendizado adaptativo sob a forma de fluxo de informações dos mantenedores e diretores para a média gerência, coordenadores, professores e funcionários, mas reduz o escopo da média e baixa gerência em comportamento de trabalho criticamente reflexivo e inibe a comunicação de novas ideias para a alta administração.

- Monitoramento dos resultados das ações implementadas: o monitoramento é realizado pelo Grupo Estratégico de forma sistemática uma vez por mês, através da realização de uma reunião de Acompanhamento Gerencial Mensal (AGM). Essa reunião tem duração estimada de 4 horas e visa acompanhar a evolução da execução dos objetivos estratégicos, através de seus indicadores, metas e planos de ação e posteriormente compartilhados com os demais envolvidos dentro da estrutura da organização. As reuniões sempre são mediadas por um orientador técnico externo, que discute o desempenho de cada indicador e sugere ações de melhoria e recuperação que são distribuídas pelos envolvidos. Também são realizadas reuniões no nível da média gerência chamadas de pré-AGMs para acompanhamento dos resultados e ajustes de rotas, caso haja algum desvio de meta. A periodicidade dessas reuniões varia de acordo com a necessidade e com o desejo de cada representante do Grupo Estratégico. Porém, identificou-se certo desconforto dos profissionais em adequar a sua 
rotina às questões do dia a dia e às atividades de acompanhamento de indicadores do BSC. Outro aspecto que vale ressaltar é em relação à autonomia na tomada de decisão pelo corpo dirigente que, de certa forma, é limitada, necessitando de aval frequente dos mantenedores.

- Utilização de incentivos e sanções: desde a implantação do BSC no CELDV são traçadas metas de desempenho que são acompanhadas periodicamente e, quando alcançadas, são distribuídos incentivos financeiros ou de outra natureza para os funcionários.

- Revisão da estratégia: anualmente é realizada uma revisão do mapa estratégico que, conforme relatado, não produz mudanças significativas. A cada quatro anos são realizadas revisões da estratégia deliberada que envolvem a reavaliação da missão, visão e valores da empresa.

Constatou-se assim que o CELDV, tendo uma estrutura consolidada de gestão e execução estratégica usando um SCG baseado no BSC e usando algumas das ferramentas recomendadas (Kaplan e Norton, 2008), convivia com lacunas: apesar de todos os profissionais entrevistados disporem de uma visão clara dos indicadores estratégicos que estavam envolvidos, ficou evidente que nem todos tinham o conhecimento do mapa estratégico da empresa e não sabiam claramente as relações de causa e efeito dos seus indicadores com os objetivos estratégicos.

\section{O surgimento da estratégia emergente}

A estratégia emergente identificada surgiu a partir da mudança no contexto externo das escolas que se dedicam ao Ensino Médio, com a introdução do Exame Nacional do Ensino Médio (ENEM). O ENEM, uma prova de abrangência nacional, criada para avaliar anualmente o aprendizado dos alunos do Ensino Médio, teve em sua primeira aplicação em 1998 e um total de 157.221 pessoas realizaram o exame. Desde então, o número de participantes tem aumentado gradativamente. Os resultados do ENEM, foram, posteriormente, incluídos nos processos seletivos das universidades públicas federais (Ministério da Educação, 2018).

Para os objetivos do caso pesquisado é importante destacar três mudanças ocorridas no processo do ENEM que influenciaram o contexto da organização estudada:

- Em 2004 uma modificação introduzida pelo MEC passou a divulgar as médias obtidas pelos alunos de cada escola na prova do ENEM: foi o ponto de partida para a criação do ranking das escolas do Ensino Médio baseado nos resultados do ENEM, por meio do qual a posição de uma escola é determinada exclusivamente pelo desempenho de seus alunos na prova;

- Em 2009 foi introduzido um novo modelo de prova para o Enem, com a proposta de unificar o concurso vestibular das universidades federais brasileiras;

- Em 2012 a Universidade de Brasília (UnB) passou a destinar 25\% de suas vagas para o Sistema de Seleção Unificado (SISU) através do ENEM.

Pode-se dizer que já existia uma inquietação de parte dos professores e coordenadores do CEDLV para aprofundar os seus conhecimentos sobre a estrutura de provas do ENEM, mas este 
movimento interno ganhou força entre os anos de 2009 a 2011 ao mesmo tempo em que se intensificaram pressões da comunidade de pais e alunos em prol do ENEM. Na verdade, a instituição viu os seus números de aprovações caírem e, consequentemente, as colocações de suas unidades no ranking brasileiro despencarem entre 2009 e 2012: na unidade Asa Sul, caindo da $350^{\circ}$ colocação para a $555^{\circ}$; na unidade Asa Norte da $196^{\circ}$ colocação para $464^{\circ}$; e na unidade Taguatinga da $258^{\circ}$ colocação para $375^{\circ}$. Em 2014, caiu ainda mais em comparação com os principais concorrentes no Distrito Federal: comparando com 2012, a Unidade Asa Sul passou da $10^{\circ}$ para a $13^{\circ}$, a Unidade Asa Norte passou da $9^{\circ}$ para a $11^{\circ}$ e a Unidade Taguatinga passou da $7^{\circ}$ para a $12^{\circ}$, conforme reforçado pelo relato do entrevistado E2:

Analisando a série histórica do Enem, entendíamos que tínhamos um patamar de aprovação satisfatório, mas percebemos até diante a concorrência mais acirrada se organizando com processos mais focados no Enem, que a nossa classificação não estava mais satisfatória.

Porém, neste período de queda gradativa, nenhuma ação estratégica coordenada foi tomada pelos dirigentes da organização e não houve nenhuma demanda adicional para os professores e coordenadores de curso. Entre 2012 e 2014, a escola começou a desenvolver ações de forma integrada para a preparação do seu corpo docente e revisão do programa pedagógico para atendimento das necessidades de conteúdo do ENEM.

A comunidade acadêmica da casa vinha exercendo uma pressão para adoção do modelo ENEM, principalmente pelo fato de, em 2012, a UnB ter disponibilizado $25 \%$ de suas vagas para o ENEM e a mídia nacional e local destacou em suas publicações sobre ranking no Distrito Federal e no Brasil.

Foi em 2014 que houve a incorporação da estratégia emergente "preparação para o ENEM" no BSC do CEDLV, com a criação de uma estrutura dedicada para este fim e ações contundentes para melhoria da escola no ranking do ENEM (Figura 1). Além disso, foi definida a distribuição de bônus para todos os funcionários para atingimento de meta baseada no melhor posicionamento da escola no ranking do ENEM. 
Figura 1 - Mapa estratégico Centro Educacional Leonardo Da Vinci

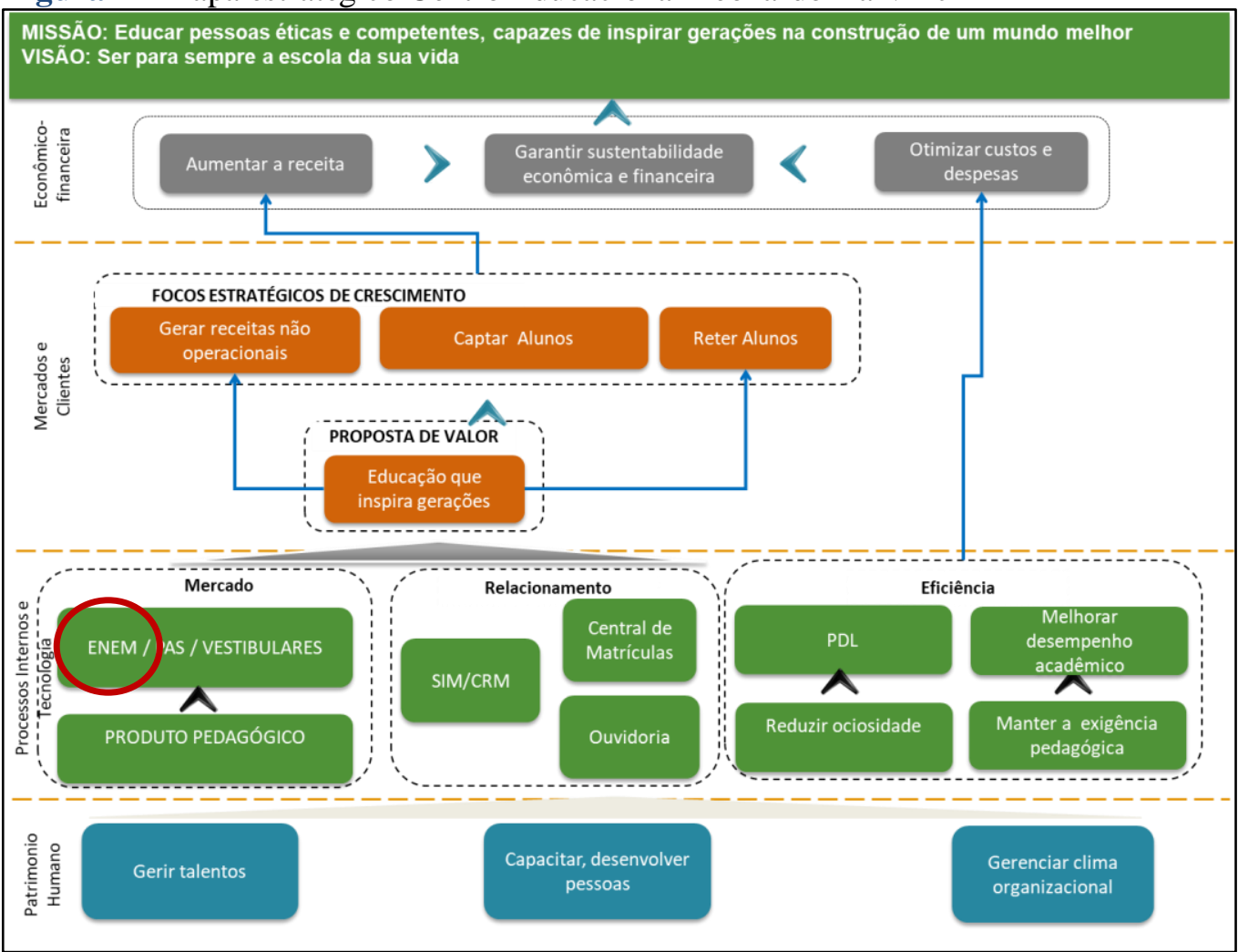

Fonte: Sistema de Gestão Estratégica Leonardo Da Vinci em 20/04/18.

De 2015 em diante, ocorreu a reestruturação do planejamento pedagógico do $3^{\circ}$ ano do Ensino Médio, de forma que todo o conteúdo fosse passado no $1^{\circ}$ semestre e o $2^{\circ}$ semestre dedicado à revisão de conteúdos e resolução de exercícios das provas do ENEM. Uma equipe dedicada passou a estudar as provas, desenvolver e responder simulados, avaliar e acompanhar os alunos ao longo do curso, especialmente do $3^{\circ}$ ano do Ensino Médio. As pressões externas da comunidade acadêmica, especialmente da mídia e dos pais dos alunos, continuaram forte. Em 2017, o MEC decidiu não realizar mais a divulgação dos rankings do ENEM.

Para melhor compreensão do processo do aparecimento e percurso da estratégia emergente identificada no CEDLV até a sua total incorporação e consolidação no plano estratégico, foi desenvolvida uma linha do tempo com as principais ações tomadas internamente pela escola, comparada com os movimentos e pressões externas da comunidade educacional (pais, alunos, concorrentes, parceiros, MEC, mídia). Esta linha do tempo teve o seu corte inicial em 2009, quando foi introduzido um novo modelo de prova para o Enem, com a proposta de unificar o concurso vestibular das universidades federais brasileiras. 
Tabela 1 - Linha do tempo do percurso da estratégia emergente até a sua total incorporação e consolidação no plano estratégico

\begin{tabular}{|c|c|c|c|}
\hline Ano & $\begin{array}{c}\text { Eventos Externos } \\
\text { (alunos, pais, concorrência, } \\
\text { parceiros, mídia, MEC) }\end{array}$ & $\begin{array}{l}\text { Ações internas } \\
\text { (CEDLV) }\end{array}$ & $\begin{array}{l}\text { Status } \\
\text { BSC }\end{array}$ \\
\hline 2009 & $\begin{array}{l}\text { Exame ENEM totalmente } \\
\text { revisado, com o aumento do } \\
\text { número de questões. } \\
\text { Unificação do vestibular das } \\
\text { universidades federais } \\
\text { brasileiras. } \\
\text { Provas questionadas, erros no } \\
\text { gabarito, cadernos furtados e } \\
\text { provas adiadas. } \\
\text { Alunos com baixo interesse } \\
\text { na prova, resolução de } \\
\text { questões e simulados. } \\
\text { Algumas escolas de Brasília } \\
\text { se estruturaram para } \\
\text { atendimento aos requisitos do } \\
\text { ENEM. }\end{array}$ & $\begin{array}{l}\text { Debate interno entre os professores } \\
\text { sobre o ENEM: mais antigos sendo } \\
\text { mais resistentes, reduziam a } \\
\text { credibilidade da prova. } \\
\text { Professores e coordenadores começam } \\
\text { a aprofundar, por iniciativa própria, } \\
\text { seus conhecimentos sobre o novo } \\
\text { modelo de provas do ENEM e tirar } \\
\text { dúvidas dos alunos. }\end{array}$ & $\begin{array}{l}\text { Sem } \\
\text { alteração } \\
\text { significativa }\end{array}$ \\
\hline 2010 & $\begin{array}{l}\text { Mídia dá mais visibilidade ao } \\
\text { ranking do ENEM. } \\
\text { Escolas concorrentes de } \\
\text { Brasília alinham conteúdos ao } \\
\text { ENEM. } \\
\text { Pais e alunos questionam } \\
\text { sobre a posição da escola no } \\
\text { ranking e ela busca uma } \\
\text { estratégia sobre o assunto. } \\
\text { Alunos buscam auxílio para } \\
\text { entendimento do ENEM e } \\
\text { resolução de questões de } \\
\text { forma pontual. } \\
\text { Vazamento de informações } \\
\text { sigilosas e a Justiça do Ceará } \\
\text { suspende os exames em todo } \\
\text { o território nacional. }\end{array}$ & $\begin{array}{l}\text { Debate interno sobre ENEM continua: } \\
\text { professores mais antigos sendo mais } \\
\text { resistentes e mais novos, mais abertos. } \\
\text { Alguns professores e coordenadores } \\
\text { continuam a aprofundar, por iniciativa } \\
\text { própria, seus conhecimentos sobre o } \\
\text { modelo do ENEM e repassam este } \\
\text { conhecimento em sala de aula de } \\
\text { forma esporádica. } \\
\text { Nenhuma ação estratégica específica } \\
\text { ou demanda adicional aos professores } \\
\text { e coordenadores. }\end{array}$ & $\begin{array}{l}\text { Sem } \\
\text { alteração } \\
\text { significativa }\end{array}$ \\
\hline 2011 & $\begin{array}{l}\text { A mídia nacional e local } \\
\text { destaca o ranking ENEM no } \\
\text { DF e no Brasil. } \\
\text { O Serviço de Orientação ao } \\
\text { Vestibulando registra } \\
\text { questionamentos mais } \\
\text { contundentes dos alunos e } \\
\text { pais para uma atitude mais } \\
\text { firme da escola em relação à } \\
\text { preparação para o ENEM. } \\
\text { Alunos buscam auxílios } \\
\text { pontuais para entendimento } \\
\text { do ENEM e resolução de } \\
\text { questões e simulados. } \\
\text { A prova foi aplicada em } \\
1.602 \text { cidades com abstenção } \\
\text { em torno de } 25 \% \text {. }\end{array}$ & $\begin{array}{l}\text { Movimento geral mais forte dos } \\
\text { professores e coordenadores para } \\
\text { aprofundar os seus conhecimentos } \\
\text { sobre a estrutura de provas do ENEM. } \\
\text { Dúvidas sobre a prova do ENEM, } \\
\text { resoluções de questões e simulados } \\
\text { repassados aos alunos em sala de aula } \\
\text { e em horários alternativos. } \\
\text { Professores e coordenadores } \\
\text { pressionam a direção da escola para o } \\
\text { desenvolvimento de um projeto para o } \\
\text { ENEM. } \\
\text { Nenhuma ação estratégica específica é } \\
\text { adotada. } \\
\text { A escola registra evasão superior à } \\
\text { média histórica. }\end{array}$ & $\begin{array}{l}\text { Sem } \\
\text { alteração } \\
\text { significativa }\end{array}$ \\
\hline
\end{tabular}


Melo, L. G. V., \&, Bernardes, M. E. B. (2020, July/Sept.). O processo de incorporação de estratégias emergentes por sistemas de controle de gestão: evidências a partir de um estudo de caso com BSC

\begin{tabular}{|c|c|c|c|}
\hline Ano & $\begin{array}{c}\text { Eventos Externos } \\
\text { (alunos, pais, concorrência, } \\
\text { parceiros, mídia, MEC) }\end{array}$ & $\begin{array}{l}\text { Ações internas } \\
\text { (CEDLV) }\end{array}$ & $\begin{array}{l}\text { Status } \\
\text { BSC }\end{array}$ \\
\hline 2012 & $\begin{array}{l}\text { A UnB disponibiliza } 25 \% \text { de } \\
\text { suas vagas para o SISU } \\
\text { (ENEM). } \\
\text { A mídia nacional e local } \\
\text { destaca o ranking ENEM no } \\
\text { DF e no Brasil. } \\
\text { Pressão mais forte da } \\
\text { comunidade para um melhor } \\
\text { no posicionamento do } \\
\text { CEDLV ENEM. } \\
\text { O Exame teve um número } \\
\text { recorde de pré-inscritos: } \\
\text { totalizando 6.497.466. O } \\
\text { Governo Federal investe para } \\
\text { evitar possíveis fraudes e } \\
\text { mudanças na correção. }\end{array}$ & $\begin{array}{l}\text { A escola registra evasão superior à } \\
\text { média histórica. } \\
\text { O corpo estratégico da escola decidiu, } \\
\text { na AGM de março de } 2012 \text {, criar o } \\
\text { Projeto ENEM e, em abril de 2012, foi } \\
\text { apresentado o Projeto - Melhorias do } \\
\text { Resultado do ENEM. } \\
\text { Foram realizados ajustes nos } \\
\text { planejamentos pedagógicos, visando } \\
\text { atender ao exame. } \\
\text { Foi criado um curso especializado } \\
\text { (com o material do parceiro Ari de Sá) } \\
\text { para a preparação dos alunos } \\
\text { interessados na prova do ENEM. } \\
\text { Foi iniciada uma formação continuada } \\
\text { para os professores e coordenadores } \\
\text { sobre a prova do ENEM. }\end{array}$ & $\begin{array}{lr}\text { Criação do } \\
\text { projeto } \\
\text { ENEM } \\
\text { mas } & \text { não } \\
\text { consta } & \text { do } \\
\text { BSC } & \end{array}$ \\
\hline 2013 & $\begin{array}{l}\text { A mídia nacional e local } \\
\text { destaca o ranking do ENEM } \\
\text { no Distrito Federal e no Brasil. } \\
\text { Novo recorde de candidatos } \\
\text { inscritos: } \\
\text { estudantes }\end{array}$ & $\begin{array}{l}\text { Evasão da escola acima da média } \\
\text { histórica. } \\
\text { Continuidade do curso de preparação } \\
\text { para o ENEM com simulados e } \\
\text { resoluções de questões com o parceiro. } \\
\text { Contratação de um professor para } \\
\text { analisar as provas e resultados do } \\
\text { ENEM e propor medidas de melhoria } \\
\text { contínua. } \\
\text { Continuação do curso de formação } \\
\text { para os professores e coordenadores } \\
\text { sobre a prova, questões e conteúdo a } \\
\text { ser passado em sala de aula. }\end{array}$ & $\begin{array}{l}\text { Sem } \\
\text { alteração } \\
\text { significativa }\end{array}$ \\
\hline 2014 & $\begin{array}{l}\text { A mídia nacional e local } \\
\text { destaca em suas publicações o } \\
\text { ranking do ENEM no Distrito } \\
\text { Federal e no Brasil. } \\
\text { Novo recorde de inscritos no } \\
\text { ENEM: } 9.519 .827 \text { estudantes. } \\
\text { O Resultado por escola do } \\
\text { ENEM } 2014 \text { revelou a } \\
\text { prática, entre as escolas } \\
\text { particulares, de separar os } \\
\text { melhores alunos em unidades } \\
\text { e/ou CNPJs diferentes para } \\
\text { apresentarem melhores } \\
\text { resultados por casa. }\end{array}$ & $\begin{array}{l}\text { Evasão da escola acima da média } \\
\text { histórica. } \\
\text { Incorporação da Estratégia Emergente } \\
\text { de preparação para o ENEM no BSC e } \\
\text { Planejamento Estratégico da } \\
\text { Instituição com o objetivo de melhorar } \\
\text { a posição no ranking, evitar evasão e } \\
\text { prospectar novos alunos. } \\
\text { Foi contratado um coordenador do } \\
\text { ENEM para a análise de resultados } \\
\text { internos (simulados), externos e } \\
\text { análise dos concorrentes (microdados } \\
\text { do INEP). } \\
\text { Manutenção do curso de formação } \\
\text { para os professores e coordenadores } \\
\text { sobre a prova, questões e conteúdo a } \\
\text { ser passado em sala de aula. } \\
\text { Definição de um bônus financeiro } \\
\text { extra para os professores, em função } \\
\text { da colocação da escola no Ranking, } \\
\text { além da participação nos resultados. A } \\
\text { Meta era manter as três unidades entre } \\
\text { as } 10 \text { melhores no ranking e pelo } \\
\text { menos uma unidade entre as } 5 \\
\text { melhores em } 2014 \text {. }\end{array}$ & $\begin{array}{l}\text { Incorporado } \\
\text { no Mapa } \\
\text { Estratégico } \\
\text { o objetivo } \\
\text { de } \\
\text { preparação } \\
\text { para o } \\
\text { ENEM }\end{array}$ \\
\hline 2015 & $\begin{array}{l}\text { A mídia nacional e local } \\
\text { destaca em suas publicações o }\end{array}$ & Evasão da escolar se estabiliza. & $\begin{array}{l}\text { Manutenção } \\
\text { dos }\end{array}$ \\
\hline
\end{tabular}




\begin{tabular}{|c|c|c|c|}
\hline Ano & $\begin{array}{c}\text { Eventos Externos } \\
\text { (alunos, pais, concorrência, } \\
\text { parceiros, mídia, MEC) }\end{array}$ & $\begin{array}{l}\text { Ações internas } \\
\text { (CEDLV) }\end{array}$ & $\begin{array}{l}\text { Status } \\
\text { BSC }\end{array}$ \\
\hline & $\begin{array}{l}\text { ranking ENEM no Distrito } \\
\text { Federal e no Brasil. } \\
\text { A Escola Olimpo, } \\
\text { concorrente direta, reorganiza } \\
\text { todo o conteúdo do ensino } \\
\text { médio deixando o } 3^{\circ} \text { ano para } \\
\text { dedicação exclusiva aos } \\
\text { conteúdos e simulados do } \\
\text { ENEM. }\end{array}$ & $\begin{array}{l}\text { Continuidade da estratégia e ações } \\
\text { anteriores. } \\
\text { Reestruturação do planejamento } \\
\text { pedagógico do } 3^{\circ} \text { ano do ensino médio } \\
\text { de forma que o } 2^{\circ} \text { semestre ficasse } \\
\text { dedicado à revisão de conteúdos e } \\
\text { resolução de exercícios das provas do } \\
\text { ENEM. } \\
\text { Atuação para convencimento dos } \\
\text { professores mais resistentes para } \\
\text { adoção das medidas. }\end{array}$ & $\begin{array}{l}\text { objetivos } \\
\text { estratégicos } \\
\text { definidos }\end{array}$ \\
\hline 2016 & $\begin{array}{l}\text { No Distrito Federal, o } \\
\text { CEDLV foi a única escola } \\
\text { que atingiu nota máxima na } \\
\text { redação do ENEM e obteve } \\
\text { alta visibilidade nos meios de } \\
\text { comunicação. }\end{array}$ & $\begin{array}{l}\text { Evasão da escolar estável. } \\
\text { Manutenção das ações anteriores. } \\
\text { Criação do projeto multiplicadores } \\
\text { internos, com temas específicos a } \\
\text { serem desenvolvidos ao longo do ano } \\
\text { para aprimoramento do conhecimento } \\
\text { dos alunos para a análise do ENEM - } \\
\text { provas anteriores e questões } \\
\text { desafiadoras. } \\
\text { O CEDLV passa a ser a única escola } \\
\text { do DF a contar com equipe de } \\
\text { professores para confecção e } \\
\text { divulgação do simulado comentado da } \\
\text { prova na data que ela é aplicada. } \\
\text { Mudança do curso para o Bernoulli } \\
\text { para o contra turno em } 3 \text { tardes. } \\
\text { Palestras de sensibilização com os } \\
\text { alunos do ensino médio para mostrar a } \\
\text { importância do ENEM. }\end{array}$ & $\begin{array}{l}\text { Manutenção } \\
\text { dos } \\
\text { objetivos } \\
\text { estratégicos } \\
\text { definidos }\end{array}$ \\
\hline 2017 & $\begin{array}{l}\text { Fim da divulgação } \\
\text { rankings dos } \\
\text { MEC. }\end{array}$ & $\begin{array}{l}\text { Manutenção dos programas } \\
\text { anteriormente definidos. } \\
\text { Os objetivos/Metas da instituição mudam, } \\
\text { passando a ser: obter maior número de } \\
\text { aprovação nos processos seletivos da } \\
\text { UnB. } \\
\text { O CEDLV é a escola que mais tem alunos } \\
\text { aprovados pelo ENEM no DF e a escola } \\
\text { que mais aprova no PAS. }\end{array}$ & $\begin{array}{l}\text { Manutenção } \\
\text { dos } \\
\text { objetivos } \\
\text { estratégicos } \\
\text { definidos, } \\
\text { agora com } \\
\text { explicitação } \\
\text { da escola } \\
\text { para a busca } \\
\text { pela } \\
\text { obtenção de } \\
\text { maior } \\
\text { aprovação } \\
\text { na UnB. }\end{array}$ \\
\hline 2018 & $\begin{array}{l}\text { Alta procura dos alunos e pais } \\
\text { para o processo de preparação } \\
\text { para estudar fora. }\end{array}$ & $\begin{array}{l}\text { Manutenção dos } \\
\text { anteriormente definidos. }\end{array}$ & $\begin{array}{l}\text { Manutenção } \\
\text { dos } \\
\text { objetivos } \\
\text { estratégicos } \\
\text { definidos. }\end{array}$ \\
\hline
\end{tabular}

Fonte: Elaborada pelos autores.

\section{Análise do processo de evolução da estratégia emergente}

Através das análises das entrevistas e triangulação de dados, foi percebido um processo de evolução da estratégia emergente desde a ideia/necessidade até a sua implantação/consolidação e 
Melo, L. G. V., \&, Bernardes, M. E. B. (2020, July/Sept.). O processo de incorporação de estratégias emergentes por sistemas de controle de gestão: evidências a partir de um estudo de caso com BSC

incorporação no plano estratégico da organização. Este processo da estratégia emergente sugeriu as seguintes fases de evolução:

1. Ideia ou Necessidade, oriunda do contexto e internamente percebida pelo nível operacional da empresa;

2. Resistência por parte da alta administração e parte do corpo operacional;

3. Avaliação da ideia ou necessidade pelo corpo gerencial;

4. Incorporação da ideia ou necessidade no planejamento estratégico;

5. Aprimoramento das ações estratégicas que sustentam o novo objetivo estratégico incorporado.

Por meio das análises das entrevistas, identificou-se que durante o desenvolvimento de todo o ciclo de evolução houve momentos contínuos de constrição interna e externa. A constrição interna foi marcada por forças internas favoráveis e contra a incorporação da estratégia emergente, oriundas principalmente dos professores, coordenadores, gerentes, diretores e mantenedores. E a constrição externa, representada principalmente pelos alunos, pais, mídia, mercado, parceiros, concorrentes, universidades e governo que pressionavam para a adoção.

As cinco fases do ciclo de evolução foram representadas ao longo dos anos, a partir de 2009, para dar visão do processo (tempo e percurso), conforme apresentado na Tabela 2, abaixo.

Tabela 2 - Etapas do Ciclo de Evolução da Estratégia Emergente no CEDLV

\begin{tabular}{|c|c|c|}
\hline $\begin{array}{l}\text { Etapa do ciclo de } \\
\text { evolução }\end{array}$ & Período & Principais evidências \\
\hline $\begin{array}{l}\text { Fase } 1 \text { - Ideia ou } \\
\text { Necessidade }\end{array}$ & 2009 & $\begin{array}{l}\text { Desconforto de parte dos professores/coordenadores com relação à } \\
\text { estrutura pedagógica que não contemplava todos conteúdos e modelo de } \\
\text { prova do ENEM; } \\
\text { Ranking do ENEM posicionando a escola abaixo dos seus principais } \\
\text { concorrentes. }\end{array}$ \\
\hline $\begin{array}{l}\text { Fase 2- } \\
\text { Resistência }\end{array}$ & $\begin{array}{l}2009 \\
2010 \mathrm{e} \\
2011\end{array}$ & $\begin{array}{l}\text { Descrença da alta gerência e de parte dos professores e coordenadores de } \\
\text { que o conteúdo pedagógico, já consolidado há anos, poderia incorporar o } \\
\text { modelo ENEM. }\end{array}$ \\
\hline $\begin{array}{l}\text { Fase } 3 \text { - } \\
\text { Avaliação }\end{array}$ & $\begin{array}{l}2012 \mathrm{e} \\
2013\end{array}$ & $\begin{array}{l}\text { Avaliação da ideia ou necessidade pela alta administração e lançamento de } \\
\text { açães específicas e pontuais para a melhoria do ranking da escola no } \\
\text { ENEM, como a realização de ajustes nos planejamentos pedagógicos, } \\
\text { visando atender a matriz do exame; } \\
\text { Criação de um curso especializado com o material do parceiro Sistema de } \\
\text { Ensino Ari de Sá no contra turno para a preparação dos alunos interessados } \\
\text { na prova do ENEM; } \\
\text { Iniciada uma formação continuada para os professores e coordenadores sobı } \\
\text { a estruturação da prova do ENEM. }\end{array}$ \\
\hline
\end{tabular}




\begin{tabular}{|c|c|c|}
\hline $\begin{array}{l}\text { Etapa do ciclo de } \\
\text { evolução }\end{array}$ & Período & Principais evidências \\
\hline $\begin{array}{l}\text { Fase } 4 \text { - } \\
\text { Incorporação }\end{array}$ & 2014 & $\begin{array}{l}\text { Incorporação da Estratégia Emergente de preparação para o ENEM no } \\
\text { BSC, considerando a criação de uma estrutura interna para análise de } \\
\text { resultados internos (simulados), externos e análise dos concorrentes } \\
\text { (microdados do INEP); } \\
\text { Aprimoramento dos cursos de formação continuada para os professores e } \\
\text { coordenadores sobre a estruturação da prova, questões e conteúdo a ser } \\
\text { passado em sala de aula; } \\
\text { Definição de um bônus financeiro extra para os professores vinculado à } \\
\text { melhoria do posicionamento da escola no ranking. }\end{array}$ \\
\hline $\begin{array}{c}\text { Fase } 5 \text { - } \\
\text { Aprimoramento }\end{array}$ & $\begin{array}{c}2015, \\
2016, \\
2017 \mathrm{e} \\
2018\end{array}$ & $\begin{array}{l}\text { Aprimoramento das ações estratégicas definidas no mapa estratégico, } \\
\text { com a reestruturação do planejamento pedagógico do } 3^{\circ} \text { ano do ensino } \\
\text { médio; } \\
\text { Criação do projeto multiplicadores internos para o aprimoramento do } \\
\text { conhecimento dos alunos para melhor análise do ENEM e provas } \\
\text { anteriores e questões desafiadoras; } \\
\text { Início de parceria com o Bernoulli para a melhoria do curso dedicado ao } \\
\text { ENEM; } \\
\text { Realização de palestras de sensibilização com os alunos do ensino médio } \\
\quad \text { para mostrar a importância do ENEM junto com o PAS. }\end{array}$ \\
\hline
\end{tabular}

Fonte: Elaborada pelos autores.

Será apresentada a seguir uma breve descrição de cada fase do ciclo de evolução que refletiu o processo de incorporação da estratégia emergente.

\section{Fase 1 - Ideia ou Necessidade}

Esta etapa foi caracterizada principalmente por duas questões: o declínio de uma estratégia já estabelecida e/ou a ideia ou necessidade de se desenvolver algo novo ou diferente. No caso do CEDLV esta fase foi marcada por uma mudança de contexto, visto que em 2009, houve a criação do Sistema de Seleção Unificado (SISU) para ingresso nas universidades federais brasileiras, baseado em um novo modelo de prova do ENEM que exigia uma preparação mais específica dos alunos e professores. Neste momento, ocorreu um debate interno entre os professores prós e contra o ENEM. Alguns professores iniciaram um aprofundamento maior dos seus conhecimentos, por conta própria, sobre a estruturação e filosofia da prova e começaram esporadicamente a apresentar em sala de aula. Além disso, mesmo com uma demanda ainda discreta por parte dos alunos, os professores eram convocados para a resolução de dúvidas de questões e simulados. Este movimento natural veio do exterior e do interior, da base da empresa, sem a participação ou direcionamento da alta direção.

\section{Fase 2 - Resistência}

Além dos exames vestibulares tradicionais, o CEDVL centrava seu planejamento estratégico na aprovação dos alunos em universidades federais de renome e no Programa de Avaliação Seriada (PAS), adotado pela Universidade de Brasília (UnB). Desta forma, a instituição acreditava que sua estrutura 
pedagógica estava preparada para atender aos requisitos do Enem, visto o histórico de resultados positivos de aprovações nas principais universidades do Distrito Federal e do Brasil.

A fase da Resistência foi onde ocorreu a maior constrição interna e externa. O movimento interno nasceu na base, através das respostas aos questionamentos dos alunos em sala de aula, sobre questões e conteúdo do ENEM. Grande parte dos professores precisou conhecer mais profundamente a matriz de conteúdo e a prova do ENEM, por iniciativa própria, para atender às necessidades dos alunos. Contudo, este movimento ganhou força quando os alunos começaram a intensificar os questionamentos, colocando em xeque o conhecimento dos professores. Os professores, então, necessitando de melhor preparo, começaram a pressionar a média e alta gerência para isso, e esses, por sua vez, relutavam em incorporar mudanças em sua base pedagógica. A resistência interna veio também por parte dos professores mais antigos e da alta administração.

Outro aspecto levantado, principalmente nas entrevistas com o nível mais estratégico da organização, foi uma resistência em sucumbir às novas ideias e estratégias quando a empresa possuía certa liderança de mercado, no caso, pelo grande número de aprovados nos exames da UnB (DF). Para retratar isto, Moore e Adamson (2011) afirmam que nas organizações existe uma força de atração ao passado, mais concretamente incorporada ao plano estratégico/operacional do ano anterior. Segundo os autores, esse plano exerce uma força que puxa, inexoravelmente, quaisquer investimentos que buscam se afastar do seu caminho inercial. Nesse contexto, os autores recomendam introduzir uma força inercial, para repensar a organização através dos novos balizadores de mercado e reforçam a constatação de O’Reilly e Tushman (2004) de que quanto mais a inércia estrutural e cultural for institucionalizada na empresa, maior será sua arrogância e complacência com o status quo organizacional.

A Fase de Resistência também foi marcada pela constrição externa, advinda das mídias, através da divulgação dos rankings do ENEM, dos concorrentes com uma campanha de marketing focado em seu posicionamento no ranking, mas principalmente dos pais dos alunos, conforme relatado pelo entrevistado E2:

Eu faço um trabalho muito importante que é me reunir individualmente com centenas de pais de alunos todo ano. Apesar de ser muito cansativo para mim, este trabalho me permite escutar e entender as principais preocupações desses pais, mas principalmente definir diretrizes internas..., com certeza, a participação deles influenciou também para mudarmos a estratégia e adicionarmos o ENEM.

\section{Fase 3 - Avaliação}

Esta fase compreendeu um processo de avaliação da ideia, envolvendo a execução de ações de contingência, projetos pilotos e testes de hipóteses. Ela se estendeu durante os anos de 2012 e 2013. Aqui se viu uma maior participação da alta administração e do corpo gerencial.

Muito se discutia nos bastidores, pelos professores, sobre um direcionamento mais estratégico sobre a revisão do conteúdo educacional do CEDLV para a prova do ENEM, mas, a partir de abril de 
2012, foi aprovado um projeto Melhoria do Resultado do ENEM em uma AGM mensal. Nesse momento, não foram alterados os objetivos estratégicos contidos no mapa BSC da escola, mas a organização passou a reconhecer o projeto e realizar o acompanhamento rotineiro do mesmo nas AGMs mensais.

Este projeto era composto basicamente por três frentes principais: a primeira era referente à realização de ajustes nos planejamentos pedagógicos visando atender minimamente a matriz do exame do ENEM; a segunda frente tinha como objetivo a criação de um curso especializado para a preparação dos alunos interessados na prova do ENEM; e a última frente relativa à formação continuada para os professores e coordenadores sobre a estruturação da prova do ENEM. Para atender os requisitos básicos, foram realizadas modificações nos planejamentos pedagógicos para alinhar a matriz do exame, criando um curso especializado com o material de uma escola parceira do Ceará (Sistema de Ensino Ari de Sá) no contraturno das aulas para a preparação dos alunos interessados. Também foi iniciada uma formação para os professores e coordenadores sobre a estrutura e conteúdo da prova do ENEM e contratado um professor dedicado que, dentre as suas atribuições, tinha como função analisar as provas e resultados do ENEM e propor medidas de melhoria contínua no programa educacional da instituição.

\section{Fase 4 - Incorporação}

Foi durante a revisão do Planejamento de Estratégico (PE), em 2014, que a estratégia emergente de readequação da proposta pedagógica da escola com foco também no ENEM foi incorporada ao Mapa Estratégico da organização. Este objetivo estratégico denominado ENEM foi inserido dentro da perspectiva de processos internos. A partir de então, foi desenvolvido um plano de estruturação da empresa para a preparação para o ENEM, conforme relata o entrevistado E4:

Lembro que o assunto posição no ranking no ENEM tinha tomado uma proporção muito grande, oriunda da base da organização, e a alta administração estava pressionada para tomar uma decisão em relação a isto. Tivemos um resultado do ENEM muito abaixo da expectativa em 2012 e 2013, mas as ações tomadas não estavam surtindo efeito na melhoria de nosso posicionamento no ranking do ENEM. O assunto vinha se arrastando até que, em meados de 2014, tomou-se a decisão incluir o ENEM como prioridade dentro do mapa estratégico e, com isto, foi desenvolvido um plano estruturado de ataque, com a capacitação de professores, para melhorar a posição da escola neste ranking.

\section{Fase 5 - Aprimoramento}

O CEDLV entendeu, com o insucesso de algumas ações definidas, que o seu plano de ações para atender aos objetivos estratégicos necessitaria estar sempre evoluindo. Assim, nesta fase, ocorreu o aprimoramento e consolidação das ações estratégicas de forma que pudesse atender as metas estabelecidas no BSC. Primeiro, foi necessária a total reestruturação do planejamento pedagógico do $3^{\circ}$ ano do Ensino Médio. Desta forma, foi definido que todo o conteúdo do $3^{\circ}$ ano fosse passado no $1^{\circ}$ semestre e $\mathrm{o} 2^{\circ}$ semestre seria dedicado à revisão de conteúdos e resolução de exercícios das provas dos sistemas FUVEST, ENEM, PAS. Para isto, houve uma necessidade de convencimento de alguns 
professores mais resistentes para adotar as medidas. Depois, foi criado o projeto multiplicador interno com temas específicos a serem desenvolvidos pelos professores ao longo do ano. O seu objetivo era o aprimoramento do conhecimento dos alunos para melhor análise da matriz ENEM e provas anteriores, questões desafiadoras. Posteriormente, foi definida a mudança da parceria do CEDLV do Sistema de Ensino Ari de Sá (Fortaleza) para o Bernoulli (Belo Horizonte), para melhoria do curso dedicado ao ENEM no contraturno das aulas do $3^{\circ}$ ano do Ensino Médio. Também foram realizadas palestras de sensibilização com os alunos do Ensino Médio para mostrar a importância do ENEM junto com o PAS.

Conforme apresentado, as diversas fases contaram com diferentes características de constrição interna e externa, cujo entendimento é fundamental para assimilar o processo de emergência e incorporação da nova estratégia.

\section{Constrição Interna e Externa}

Analisando todo percurso da estratégia emergente, percebeu-se que ela era acompanhada por contextos de pressão interna e/ou externa constantes, favoráveis ou desfavoráveis à sua incorporação, conforme apresentado na Figura 2. Revela-se, entretanto, neste estudo de caso, que as forças de constrição favoráveis foram mais fortes do que desfavoráveis.

Dentre os principais pontos de constrição interna favoráveis à estratégia emergente, pode-se destacar:

- Debate interno entre os professores favoráveis e contra sobre a estrutura do ENEM e sua incorporação interna.

- Iniciativa de parte dos professores e coordenadores em aprofundar seus conhecimentos sobre o novo modelo de provas do ENEM por iniciativa própria.

- Questionamentos dos alunos em sala de aula sobre a estrutura e os conteúdos da prova do ENEM.

- Necessidade de realização de sessões específicas e em salas de aula para atendimentos de dúvidas dos alunos sobre questões e simulados do ENEM.

- Movimento de pressão de parte dos professores e coordenadores para o desenvolvimento de um projeto para atendimento ao ENEM.

- Resultados do CEDLV no ENEM aquém dos esperados.

Já dentre os principais pontos de constrição interna desfavoráveis à estratégia emergente, salienta-se:

- Crença pela alta administração e por parte dos professores de que a estrutura pedagógica do CEDLV, já consolidado há anos, e que sempre foi a base de sustentação dos resultados da escola, principalmente na UnB estava suficientemente embasada para também sustentar resultados do Enem. 
- Crença pela alta administração de que o exame do ENEM não seria reconhecido pela UnB como porta de entrada para o ingresso de alunos.

- Subestimação pela alta administração de que seus concorrentes diretos estavam se preparando com celeridade para um melhor posicionamento no ranking do ENEM.

- Subestimação da reação dos pais e alunos e principalmente da mídia sobre a repercussão da divulgação do ranking do ENEM.

Figura 2 - Ciclo de Evolução da Estratégia Emergente

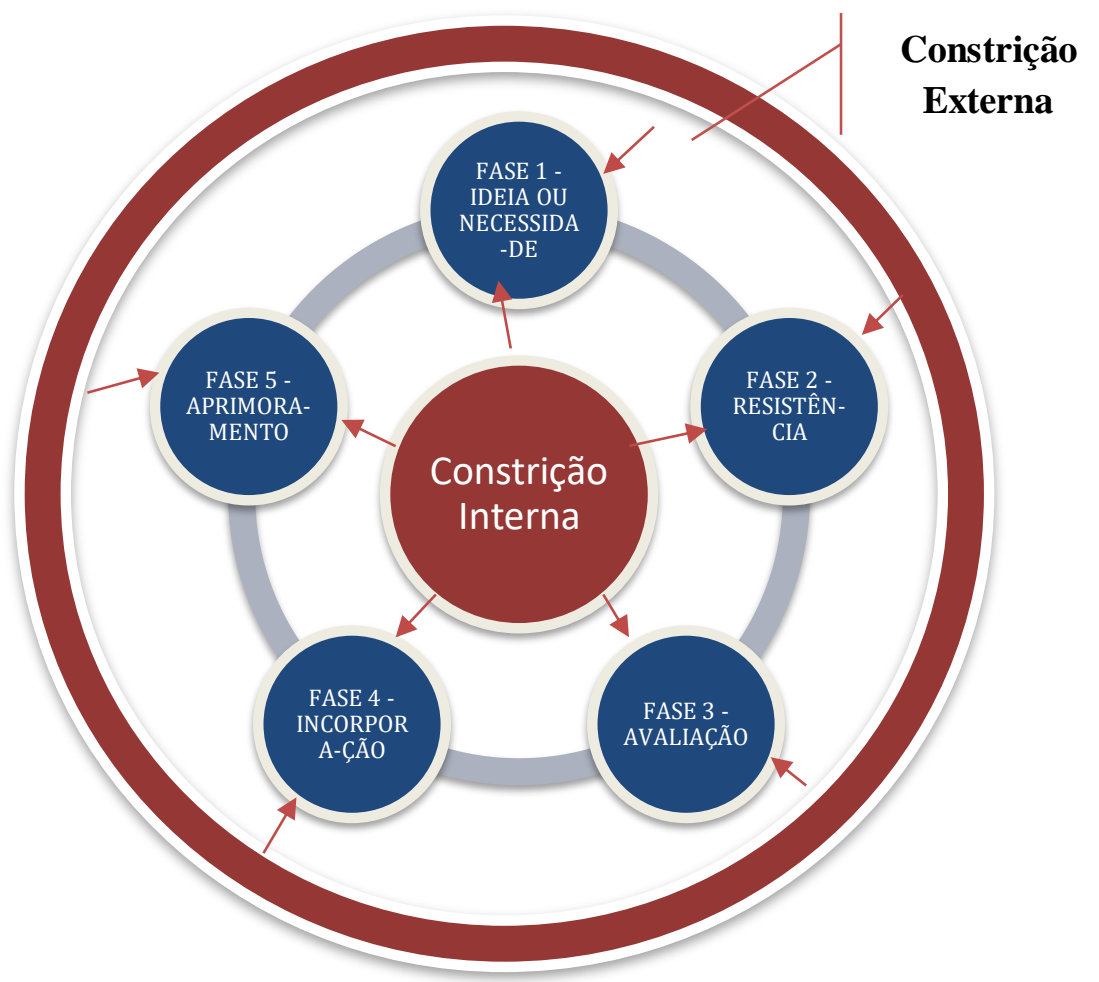

Fonte: Elaborada pelos autores.

Os principais pontos de constrição externa foram:

- Decisões do MEC:

- Criação do Programa Universidade Para Todos (PROUNI) que passou a selecionar alunos para bolsas através do ENEM e para obtenção de financiamento através do Fies (Fundo de Financiamento ao Estudante do Ensino Superior).

- Divulgação do ranking das escolas do Ensino Médio

- Criação do SISU para ingresso nas universidades federais brasileiras, com base em um novo modelo de prova do ENEM

- Disponibilização pela UnB de $25 \%$ de suas vagas para o SISU (ENEM).

- Mídia: destaque em todas as mídias do ranking das escolas de Ensino Médio, num primeiro momento, em nível nacional e posteriormente em nível distrital, visto que a mídia local iniciou uma divulgação mais forte quando a UnB aderiu ao ENEM. 
- Concorrentes diretos: a preparação mais antecipada dos concorrentes diretos, muito puxada por atuarem em outros estados e cidades que já tinham despertado previamente para a importância do ENEM

- Comunidade Escolar: a constrição externa que mais contrabalanceou favoravelmente a incorporação da estratégia ao PE, conforme relata o entrevistado E2:

Como os pais e os alunos passaram a escolher para matrícula as instituições de ensino com melhor desempenho no ENEM, tornou-se estratégico para a instituição a obtenção de excelentes resultados nessa modalidade de avaliação ao final do ensino médio.

Pode-se constatar que estes movimentos internos e externos foram mais impactantes em dois momentos: o primeiro momento, marcado pela conversão dos colaboradores de linha de frente (nível operacional) na adoção da estratégia emergente - professores e coordenadores - e pela conversão de mercado, isto é, do exame do ENEM totalmente revisado pelo MEC, criação pelo Governo Federal dos programas SISU, FIES e Ciência Sem Fronteira e divulgação do ranking do ENEM. Já o segundo momento, estereotipado pela conversão dos stakeholders estratégicos, principalmente os mantenedores e pela conversão do mercado local, deslindado neste estudo pelo Distrito Federal (DF) - disponibilização de $25 \%$ das vagas da UnB para o ENEM e maior destaque na mídia local. Estes movimentos tiveram a duração de três anos cada e estão sintetizados na Tabela 3, abaixo:

Tabela 3 - Movimentos de Conversão - Constrição Interna e Externa

\begin{tabular}{|c|c|c|c|}
\hline Momentos & Constrição Interna & Constrição Externa & Período \\
\hline & Conversão & Conversão de Mercado Global & \\
\hline 1 & $\begin{array}{l}\text { Operacional } \\
\text { (Professores e } \\
\text { Coordenadores) }\end{array}$ & $\begin{array}{l}\text { (Criação pelo governo federal dos programas SISU, } \\
\text { FIES e Ciência Sem Fronteira - e divulgação do ranking } \\
\text { do ENEM }\end{array}$ & $\begin{array}{c}2009,2010 \\
\text { e } 2011\end{array}$ \\
\hline 2 & $\begin{array}{l}\text { Conversão } \\
\text { Estratégica } \\
\text { (Mantenedores) }\end{array}$ & $\begin{array}{c}\text { Conversão de Mercado Local } \\
\text { (Disponibilização de } 25 \% \text { das vagas da UnB para o } \\
\text { ENEM e maior destaque na mídia local) }\end{array}$ & $\begin{array}{c}2012,2013 \\
\text { e } 2014\end{array}$ \\
\hline
\end{tabular}

Fonte: Elaborada pelos autores.

\section{Conclusões}

Este estudo se propôs a desvendar como ocorre o processo de incorporação de estratégias emergentes utilizando um sistema de controle de gerenciamento com base no Balanced Scorecard. Para isso, pretendeu-se compreender como as novas estratégias emergem dentro do ciclo de implementação da estratégia que conta com um SCG, entender o percurso até a sua total incorporação e consolidação no plano estratégico, e sugerir melhorias para deixar o modelo mais flexível e dinâmico. A metodologia de pesquisa utilizada foi a do estudo do caso do Centro Educacional Leonardo Da Vinci (CEDLV), organização que monitora a implementação de sua estratégia através do uso do SCG baseado no BSC e 
que incorporou uma estratégia emergente a partir das mudanças ocorridas em seu contexto com a introdução do ENEM.

A estratégia emergente identificada foi a de readequação da proposta pedagógica da escola para também focar no ENEM. Essa estratégia foi considerada emergente porque seus primeiros movimentos de constrição foram realizados em 2009 pela base da organização (professores e coordenadores) e somente em 2014, após a combinação de movimentos internos e externos, a estratégia foi efetivamente incorporada ao mapa estratégico.

Foi identificado um processo de evolução da estratégia emergente em fases, desde os primeiros movimentos até a sua incorporação no plano estratégico da organização: a primeira fase foi a da ideia ou necessidade, oriunda do contexto e internamente percebida pelo nível operacional da empresa; a segunda fase correspondeu à resistência por parte da alta administração e por parte do corpo operacional; a terceira foi a fase da avaliação da ideia/necessidade pelo corpo gerencial; a quarta fase foi onde se deu a incorporação no planejamento estratégico; e a quinta a fase refere-se ao aprimoramento das ações estratégicas que sustentam o novo objetivo estratégico vinculado.

Através do estudo realizado, pode-se observar, por um lado, que o uso de um SCG como o BSC, além de fortalecer o controle formal pela alta administração, de fato reduzia a capacidade dos funcionários para contribuírem com novas ideias, conforme já havia sido alertado por Norreklit (2000) e Antonsen (2014); por outro lado, este estudo também demonstrou que a combinação de movimentos de stakeholders internos, oriundos da base da organização - professores e colaboradores - e stakeholders externos advindos do mercado, da comunidade envolvida, de órgãos setoriais de governo e da mídia, fortaleceram a emersão de ideias e suas transformações em estratégias deliberadas. Esses achados estão alinhados com os estudos de Frezatti et al. (2014) que constataram que a associação entre os estímulos externos e a tensão dinâmica corroboram afetando o horizonte temporal, ou mesmo o grau de rigidez com que uma estratégia é seguida dentro do BSC.

Sendo assim, este estudo de caso, apesar de parcialmente compartilhar das visões de Antonsen (2014), Norreklit (2000) e de Voelpel, Leibold e Eckhoff (2006), que enxergam o BSC como um processo interno de desenvolvimento organizacional fundamentalmente controlado pela alta gerência, reforça os achados de Lowe \& Jones (2004) que acolhe a possibilidade do SCG se abrir para desenvolvimento de estratégias bottom up, no caso, desde que acompanhadas de movimentos contínuos e progressivos de constrições internas e externas.

O estudo confirmou o que Mintzberg (1987) e também Kaplan e Norton $(1996,2007)$ relataram, que na prática, tanto as estratégicas hierárquicas quanto as emergentes coexistem. Além de que os processos de gestão construídos em torno da estratégia articulados em um SCG como o BSC, precisam prover oportunidades para que as novas ideias que emergem da base da organização sejam consideradas para aproveitamento de novas oportunidades e direções estratégicas. O estudo identificou certo distanciamento da alta administração dos profissionais da operação, no que tange à divulgação e acompanhamento do plano estratégico. Mesmo que o Grupo Estratégico instituído tivesse esta função 
mais macro, havia uma sensação de hiato entre eles e o time da operação (que ficava relegado ao curto prazo e à gestão dos indicadores operacionais, dificultando o desenvolvimento de argumentos mais estratégicos para a proposição de novas ideias e projetos). Desta forma, constata-se que um SCG pode ter seu uso limitado como ferramenta de gerenciamento da operação, perdendo o foco estratégico do seu progresso no longo prazo. Recomenda-se, assim, ações de melhorias na comunicação e no envolvimento dos níveis operacionais nas discussões estratégicas para uma implementação mais bem-sucedida.

Não se pode deixar de observar que esta pesquisa tem a limitação típica dos estudos de caso. Portanto, apesar de permitir generalizações analíticas, seus resultados e conclusões precisam ser replicados através da avaliação de múltiplos estudos de caso. A proposta do ciclo de evolução pode ser mais desenvolvida. Assim, esse estudo pode inspirar pesquisas futuras para se investigar melhor as cinco fases do ciclo de evolução da estratégia emergente com as forças contínuas de constrições internas e externas. Pode-se investigar em outras empresas e em outros setores. É interessante entender melhor também o quanto e quando as forças de constrição pesam para o lado do estabelecimento da estratégia emergente e se há uma potencial chance de esta ser incorporada mais rapidamente. Recomenda-se também que os pesquisadores se atentem para as variáveis aqui estabelecidas dentro do ciclo de incorporação da estratégia emergente para avaliar se os seus comportamentos condizem com os identificados nessa pesquisa e refinar o modelo proposto, evoluindo para uma representação mais rica da realidade.

\section{Referências}

Americano, G., \& Fleck, D. (2015). Implementação de estratégia como um processo de mudança organizacional. Relatórios Coppead, v. 417, n. Fevereiro.

Antonsen, Y. (2014). The downside of the balanced scorecard: A case study from Norway. Scandinavian Journal of Management, 30(1), 40-50.

Balogun, J., \& Johnson, G. (2005). From intended strategies to unintended outcomes: The impact of change recipient sensemaking. Organization studies, 26(11), 1573-1601.

Bernardes, M. E. B., Dias, C. G., \& Drummond, C. G. D. (2008). Processo de implementação de estratégia: onde estamos e como podemos prosseguir. Anais do XXXII Encontro da ANPAD, Rio de Janeiro.

Bower, J. L. (1970). Managing the resource allocation process: a study of corporate planning and investment. Harvard Business School Division of Research, Boston, MA

Burgelman, R. A. (1983). Corporate entrepreneurship and strategic management: Insights from a process study. Management science, 29(12), 1349-1364.

Centro Educacional Leonardo Da Vinci. (19/07/2018). O Leonardo: Quem somos. Fonte: Site do Centro Educacional Leonardo Da Vinci: https://www.leonardoonline.com.br/.

Correio Brasiliense. (19 de 09 de 2018). Inicio: Capa Ideb: confira ranking das escolas do Distrito Federa. Fonte: Site do Correio Brasiliense: https://www.correiobraziliense.com.br/app/noticia/eu- 
estudante/ensino_educacaobasica/2018/09/06/ensino_educacaobasica_interna,704465/ideb-confiraranking-das-escolas-do-distrito-federal.shtml.

Coon, B., \& Wolf, S. (2005). The alchemy of strategy execution. Employment relations today, 32(3), 19-30.

Daft, R. L., \& Macintosh, N. B. (1984). The nature and use of formal control systems for management control and strategy implementation. Journal of Management, 10(1- Spring), 43-66.

Eisenhardt, K. (1989). Building theories from case study research, 14(4), 532-550.

Frezatti, F., Bido, D. de S., Cruz, A. P. C. da., Machado, M. J. de C. (2014). O papel do Balanced Scorecard na gestão da inovação. RAE-Revista de Administração de Empresas, 54(4), 381-392.

Gomes, J. S. \& Salas, J. A.; (1997) Controle de gestão: uma abordagem contextual e organizacional Textos e casos. Atlas, São Paulo.

Hamel, G. (2009). Moon shots for management. Harvard business review, 87(2), 91-98.

Jaworski, B. J.; Macinnis, D. J. Marketing jobs and management controls: toward a framework: EBSCOhost. Journal of Marketing Research (JMR), v. 26, n. 4, p. 406-419, 1989.

Jazayeri, M.; Scapens, R. W. The business values scorecard within bae systems: The evolution of a performance measurement system. The British Accounting Review, v. 40, n. 1, p. 48-70, mar. 2008.

Jordão, R. V. D. \& Casas Novas, J. L. (2013). A study on the use of the balanced scorecard for strategy implementation in a large Brazilian mixed economy company. Journal of technology management \& innovation, 8(3), 98-107.

Kaplan, R. S. \& Norton, D. P. (1996). Using the balanced scorecard as a strategic management system. Havard Business Review. , v. 74, n. 1, p. 75-85.

Kaplan, R. S. \& Norton, D. P. (1996) The balanced scorecard: Translating strategy into action Harvard Business Review Disponível Em: http://Ieeexplore.Ieee.Org/Document/628729/.

Kaplan, R. S., \& Norton, D. P. (2001). Transforming the balanced scorecard from performance measurement to strategic management: Part II. Accounting horizons, 15(1), 87-104.

Kaplan, R. S., \& Norton, D. P. (2006). How to implement a new strategy without disrupting your organization. Harvard Business Review, 84(3), 100.

Kaplan, R. S. \& Norton, D. P. (2007) Using the Balanced Scorecard. Harvard Business Review, v. 85, n. $7 / 8$, p. $150-161$.

Kaplan, R. S., \& Norton, D. P. (2008). Mastering the management system. Harvard Business Review, 86(1), 62.

Langley, A. (2007). Process thinking in strategic organization. Strategic Organization, 5(3), 271-282.

Lowe, A., \& Jones, A. (2004). Emergent Strategy and the Measurement of Performance: The Formulation of Performance Indicators at the Microlevel. Organization Studies, 25(8), 1313-1337.

Mariotto, F. L. (2003). Mobilizando estratégias emergentes. Revista de Administração de Empresas, 43(2), 78-93. 
Mariotto, F. L.; Zanni, P. P.; De Moraes, G. H. S. M. (2014) What is the use of a single-case study in management research? RAE-Revista de Administración de Empresas, v. 54, n. 4, p. 358-369.

Ministério da Educação (MEC). (19/09/2018). Legislação. SISU - Sistema de Seleção Unificada: http://sisu.mec.gov.br/legislacao.

Mintzberg, H. (1978). Patterns in strategy formation. Management science, 24(9), 934-948.

Mintzberg, H. (1987). Crafting Strategy. Harvard Business Review, 65(4 - Jul/Aug), 66-75.

Mirabeau, L., \& Maguire, S. (2014). From autonomous strategic behavior to emergent strategy. Strategic Management Journal, 35(8), 1202-1229.

Moore, G. A., \& Adamson, R. (2011). Escape velocity: Free your company's future from the pull of the past. HarperBusiness.

Neely, A. (2008). Does the balance scorecard work: an empirical investigation. Business, n. 1620.

Noda, T., \& Bower, J. L. (1996). Strategy making as iterated processes of resource allocation. Strategic management journal, 17(S1), 159-192.

Norreklit, H. (2000). The balance on the balanced scorecard a critical analysis of some of its assumptions. Management accounting research, 11(1), 65-88.

O'Reilly III, C. A., \& Tushman, M. L. (2004). The ambidextrous organization. Harvard business review, 82(4), 74.

Pettigrew, A. M. (1992). The Character and Significance of Strategy Process Research. Strategic Management Journal, 13(8- Winter- Special Issue), 5-16.

Simons, R. (1991) Strategic orientation and top management attention to control systems. Strategic Management Journal 12/1: 49-62.

Simons, R. (1994). How new top managers use control systems as levers of strategic renewal. Strategic management journal, 15(3), 169-189.

Simons, R., (1995) Levers of Control, Boston, Harvard Business School Press, 1995.

Vergara, S. C. (2005). Métodos de Pesquisa em Administração São Paulo: Ed Atlas AS.

Voelpel, S. C., Leibold, M., \& Eckhoff, R. A. (2006). The tyranny of the Balanced Scorecard in the innovation economy. Journal of Intellectual Capital, 7(1), 43-60.

Whittington, R. (2007). Strategy Practice and Strategy Process: Family Differences and the Sociological Eye. Organization Studies, 28(10), 1575-1586.

Yin, R. K. (1994). Case Study Research: design and methods. Thousand Oaks: Sage Publications. 